\title{
Endostatin expression in pancreatic tissue is modulated by elastase
}

\author{
RD Brammer', SR Bramhall² and MC Eggo*,I \\ 'Division of Medical Sciences, University of Birmingham, Birmingham B 5 2TT, UK; ${ }^{2}$ Department of Surgery, Queen Elizabeth Hospital, Birmingham B 5 \\ $2 T H, U K$
}

\begin{abstract}
Pancreatic tumours are scirrhous, avascular tumours, suggesting that they may produce angiogenesis inhibitors that suppress the growth of the vasculature to the tumour and metastases. We have sought evidence for the angiogenesis inhibitor, endostatin, in normal and cancerous pancreatic tissue. Using Western blotting, we found mature $20 \mathrm{kDa}$ endostatin in cancer tissue but not in normal tissue. Several endostatin-related peptides of higher mol wt were present in both tissues. Extracts from normal tissue were able to degrade exogenous endostatin, whereas extracts from cancer were without effect. Although the exocrine pancreas secretes inactive proenzymes of trypsin, chymotrypsin and elastase, their possible role in this degradation was examined. The trypsin/ chymotrypsin inhibitor, Glycine max, did not prevent the degradation of endostatin by normal pancreatic extracts but elastatinal, a specific inhibitor of elastase, reduced the rate of degradation. Extracts of pancreatic tumours did not express any detectable elastase activity, but an elastase ( $K_{\mathrm{m}}$ I.I mM) was expressed by extracts of normal pancreas. We conclude that endostatin is present and stable in pancreatic cancer tissues, which may explain their avascular nature, but that normal pancreatic tissue expresses enzymes, including elastase, which rapidly degrade endostatin. The stability of endostatin may have implications for its therapeutic use.

British Journal of Cancer (2005) 92, 89-93. doi:10.1038/sj.bjc.6602234 www.bjcancer.com
\end{abstract}

Published online 16 November 2004

(C) 2005 Cancer Research UK

Keywords: endostatin; pancreatic cancer; elastase; angiogenesis

Pancreatic cancer is the fifth leading cause of cancer death in the UK, and despite advances in diagnosis, surgery and adjuvant chemotherapy, the prognosis remains poor (Bramhall et al, 1995; Jolly et al, 2002). Alternative methods of treatment therefore need to be investigated. Evidence exists that growth and resultant prognosis of pancreatic tumours is dependent upon microvessel density (Ellis et al, 1998). New capillaries sprout from existing blood vessels by a process known as angiogenesis. After adolescence, angiogenesis normally only occurs during reproduction, wound healing and states of chronic inflammation. It is a prerequisite for tumour growth and metastasis because without a sufficient blood supply, tumours rarely grow beyond a few millimetres in diameter (Folkman, 1990).

Angiogenesis is dependent upon both pro- and antiangiogenic factors (Folkman and Klagsbrun, 1987). One such antiangiogenic factor is endostatin. Endostatin is a $20 \mathrm{kDa}$ fragment of the noncollagenous (NC-1) C-terminus of the basement membrane protein, collagen XVIII. Endostatin specifically inhibits endothelial cell migration, and induces cell cycle arrest and apoptosis in vitro, and in vivo, it reduces tumour growth (O'Reilly et al, 1997). Endostatin is now in clinical trials as an anticancer chemotherapeutic agent. Since collagen XVIII is a component of the vascular basement membrane, endostatin and endostatin-related proteins have been found in a variety of tissues (Saarela et al, 1998; Miosge et al, 1999). The occurrence of a broad range of endostatin-like fragments in tissues and serum suggests that collagen XVIII is

*Correspondence: Dr MC Eggo, The Medical School, University of Birmingham, Birmingham BI5 2TT, UK; E-mail M.C.Eggo@bham.ac.uk Received 30 April 2004; revised 14 September 2004; accepted 28 September 2004; published online 16 November 2004 sensitive to degradation at a number of sites by proteases (Standker et al, 1997; Sasaki et al, 1998; John et al, 1999; Ferreras et al, 2000).

Pancreatic tumours are scirrhous, avascular tumours, which suggests that the primary pancreatic tumour may produce an angiogenesis inhibitor, which suppresses the growth of the vasculature to the tumour and of metastases. Following surgical resection, removal of this angiogenesis inhibitor would result in removal of an inhibitory force acting upon the dormant micrometastases as elaborated by several authors (Folkman, 1990, 1995; Kirsch et al, 2000, 2004). The normal exocrine pancreas produces large amounts of proforms of the proteolytic enzymes trypsin, chymotrypsin and elastase, which are destined for the gastrointestinal tract. We hypothesised that pancreatic tissue contains collagen XVIII, and is therefore capable of producing endostatin from its precursor by proteolytic action of activated forms of these proteases or other proteases synthesised by the pancreas.

Evidence for the expression of collagen XVIII and endostatin in samples of both normal pancreatic tissue and pancreatic cancer was therefore sought. The regulation of endostatin production was investigated by studying endogenous protease action upon collagen XVIII and exogenous endostatin.

\section{METHODS AND MATERIALS}

\section{Preparation of tissue lysates}

Tissue samples were obtained at surgery and were frozen within $10 \mathrm{~min}$ of removal. Ethical approval was obtained for all tissue used. At all times, the tissue and the homogenates derived from the 
tissues were kept in an ice bath at $0^{\circ} \mathrm{C}$ to prevent warming and potential proteolysis. Approximately $1 \mathrm{~cm}^{3}$ sections of frozen normal pancreatic and pancreatic cancer tissue $(n=5)$ were homogenised in $2 \mathrm{ml}$ of Hank's balanced salt solution (HBSS) using a motorised homogeniser (Polytron). The homogenate was sonicated using five pulses of $30 \mathrm{~s}$ each and centrifuged at $15000 \mathrm{~g}$ for $30 \mathrm{~min}$. The supernatant was removed and stored at $-20^{\circ} \mathrm{C}$ until use. In experiments examining expression of endostatin in tumour and normal tissues, $0.1 \%$ Triton X-100 was included to aid solubilisation from membranes. The pelleted, insoluble material was dissolved by boiling in $2 \%$ sodium dodecyl sulphate (SDS) in HBSS and stored at $-20^{\circ} \mathrm{C}$ until use.

\section{Western blotting}

A volume containing $100 \mu \mathrm{g}$ of protein was used and samples were heated to $60^{\circ} \mathrm{C}$ for $30 \mathrm{~min}$ in reducing sample buffer containing $100 \mathrm{~mm} 2$-mercaptoethanol, $2 \%$ SDS and $62.5 \mathrm{~mm}$ Tris- $\mathrm{HCl} \mathrm{pH} 6.8$ before loading onto $12.5 \%$ SDS-polyacrylamide gels. Western blotting was performed as described previously using PVDF membrane (Hybond P, Amersham Pharmacia) (Michell et al, 1997). Primary antibody raised in rabbit to endostatin (Chemicon, $1: 100$ dilution) and horseradish peroxidase-labelled secondary antibodies (Santa-Cruz Ltd, 1:50000 dilution) were used with enhanced chemiluminescence detection (ECL). The specificity of the endostatin primary antibody was confirmed by preabsorption to recombinant endostatin. No proteins were identified by ECL when the primary antibody was saturated with recombinant endostatin (data not shown).

\section{Stability of endostatin in normal pancreatic tissue and pancreatic cancer tissue}

Aliquots of homogenates prepared in HBSS containing $100 \mu \mathrm{g}$ of normal or cancer tissue proteins were incubated at $37^{\circ} \mathrm{C}$ with $5 \mathrm{ng}$ of recombinant endostatin (CN Bioscience) for periods of up to $20 \mathrm{~h}$. Incubation was terminated at various time points by immersing the samples in an ice bath and adding reducing sample buffer. To test the thermal sensitivity of the reaction, $100 \mu \mathrm{g}$ of HBSS-soluble normal pancreatic extract was denatured by boiling and incubated with endostatin in the manner above. Analysis by Western immunoblotting was performed.

\section{Effect of protease inhibitors on stability of endostatin in tissue lysates}

In total, $5 \mathrm{ng}$ of endostatin was incubated for varying times up to $24 \mathrm{~h}$ at $37^{\circ} \mathrm{C}$ with $\mathrm{HBSS}$-soluble pancreatic homogenate in the presence of either a combined trypsin-chymotrypsin inhibitor from Glycine max (soybean) (Sigma), at a concentration of $100 \mu \mathrm{g}$ inhibitor per $100 \mu \mathrm{g}$ total protein, or Elastatinal (Calbiochem, Germany), a specific, irreversible elastase inhibitor, at a concentration of $100 \mu \mathrm{m}$.

\section{Elastase activity in normal and pancreatic cancer tissue}

Activity of elastase in the pancreatic tissue lysate was evaluated with a colorimetric assay using $N$-methoxysuccinyl-Ala-Ala-ProVal P-nitroanilide as a chromogenic substrate as described by Bieth and Wermuth (1973). The molar extinction coefficient of the product formed was 8800 , read at $410 \mathrm{~nm}$ in a $1 \mathrm{~cm}$ light path. Incubation was performed at room temperature on a 96-well microplate and the plate was read at intervals between 5 and $30 \mathrm{~min}$ up to a period of $24 \mathrm{~h}$. The kinetics of the HBSS-soluble pancreatic tissue homogenates was evaluated and the assay was verified using purified neutrophil elastase (Sigma, UK). The results were analysed by plotting a Lineweaver-Burk curve to determine $K_{\mathrm{m}}$ and $V_{\max }$.
All experiments were performed in triplicate to confirm reproducibility.

\section{RESULTS}

\section{Presence of collagen XVIII-endostatin in normal and cancerous pancreatic tissues}

Figure 1 shows a Western blot of extracts of proteins in the soluble fraction and the SDS-solubilised material from normal and cancerous pancreatic tissue, probed for endostatin. Immunoreactive bands are present at $120,70,36$ and $20 \mathrm{kDa}$. The larger bands contain the endostatin fragment at their $\mathrm{C}$ terminus. The soluble fraction contains collagen XVIII $(120 \mathrm{kDa})$, a $70 \mathrm{kDa}$ fragment and the NC-1 fragment $(36 \mathrm{kDa})$ in both normal pancreatic and pancreatic cancer tissue. The $20 \mathrm{kDa}$ form of mature endostatin is present in the cancer tissue but not normal tissue. The SDSsolubilised fraction contains the $36 \mathrm{kDa}$ fragment in both normal and pancreatic cancer tissue.

\section{Stability of exogenous endostatin in HBSS-soluble fractions from normal and cancer-derived pancreatic tissue}

Recombinant endostatin was incubated with the HBSS-soluble fraction from normal pancreatic tissue and its stability determined by Western blotting. Figure 2 shows its stability with time. Degradation of collagen XVIII, endogenous endostatinrelated fragments $(70$ and $36 \mathrm{kDa})$ and exogenous $20 \mathrm{kDa}$ endostatin was seen at $2 \mathrm{~h}$ with complete degradation occurring by $4 \mathrm{~h}$. The immunoreactivity of the endogenous endostatinrelated fragment at $36 \mathrm{kDa}$ was seen to diminish at $0.5 \mathrm{~h}$ and then increase to a maximum intensity at $2 \mathrm{~h}$. This increase in intensity coincided with the loss of the immunoreactivity of the band at $70 \mathrm{kDa}$.

The same experiment was repeated with HBSS-soluble extracts from pancreatic cancer tissue and the results are shown in Figure 3. Neither endogenous nor exogenous endostatin was degraded over time. Degradation of collagen XVIII and endostatin-related fragments (70 and $36 \mathrm{kDa})$ was not observed over a $4 \mathrm{~h}$ time period.

Heat treatment of the HBSS-soluble normal pancreatic extract by boiling prevented the degradation of endogenous endostatinrelated fragments and exogenous $20 \mathrm{kDa}$ endostatin (data not shown).

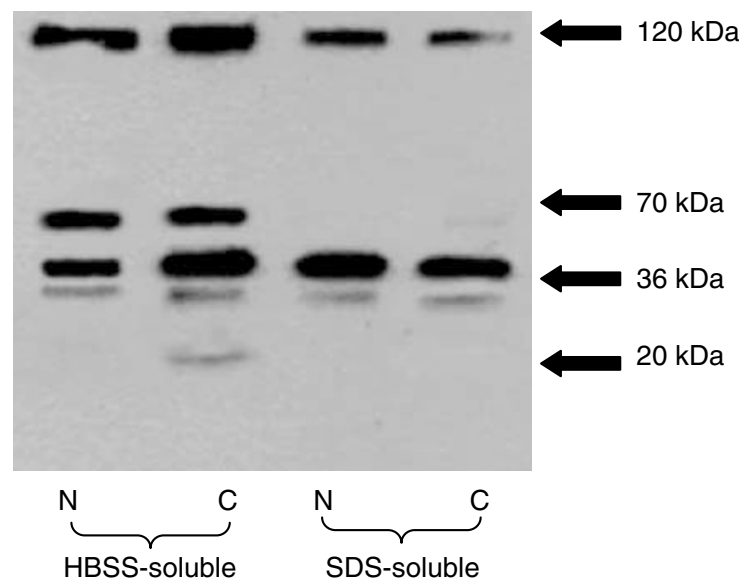

Figure I Western immunoblotting demonstrating the presence of endostatin-immunoreactive fragments in HBSS-soluble and SDS-soluble extracts from normal and cancer pancreas ( $\mathrm{N}$ - normal pancreas, $\mathrm{C}$ cancer pancreas). 


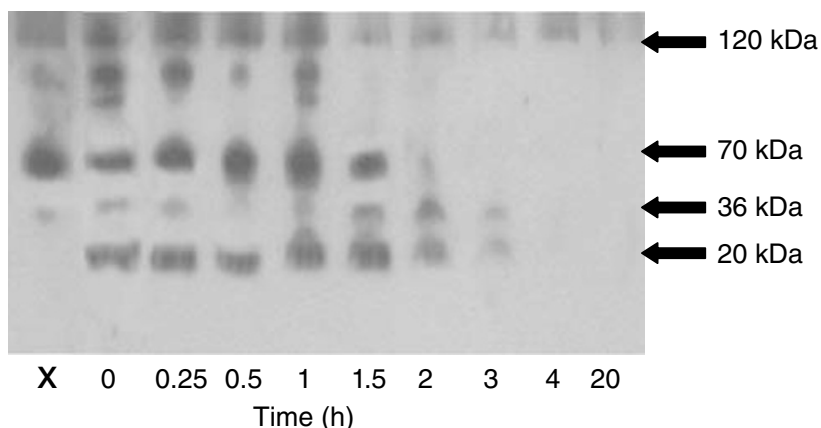

Figure 2 Western immunoblotting demonstrating that normal HBSSsoluble pancreatic homogenate degrades exogenous recombinant endostatin over time. A fixed amount of HBSS-soluble extract from normal pancreas was incubated with $5 \mathrm{ng}$ of recombinant endostatin for the time periods shown. Recombinant endostatin migrates as a single band of $20 \mathrm{kDa}$. Sample $\mathrm{x}$ is the normal pancreatic homogenate without exogenous endostatin.

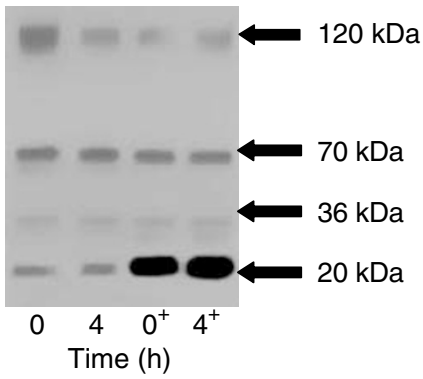

Figure 3 Western immunoblotting demonstrating that an HBSS-soluble extract from pancreatic cancer tissues does not degrade exogenous recombinant endostatin over $4 \mathrm{~h}$. Exogenous endostatin $(5 \mathrm{ng})$ was added to the samples in the lanes marked + .

Effects of protease inhibitors on endostatin degradation by HBSS-soluble extracts of pancreatic tissue

To assess the potential contribution of endogenous pancreatic proteases, trypsin and chymotrypsin, to the degradation of exogenous endostatin, we performed the same experiment described in Figure 2 in the presence of a trypsin-chymotrypsin inhibitor in excess. When endostatin was incubated with HBSSsoluble extract from normal pancreatic tissue and the inhibitor, its degradation was not prevented (Figure $4 \mathrm{~A}$ ). By $4 \mathrm{~h}$, all immunoreactive endostatin added to the sample had disappeared. The effects in Figure 2 were therefore unlikely to be due to the presence of endogenous active trypsin and chymotrypsin.

The effects of the elastase inhibitor, elastatinal, on the degradation of exogenous endostatin by an HBSS-soluble extract from normal pancreatic tissue are shown in Figure 4B. In the absence of elastase inhibitor, complete degradation of endostatin was seen by $4 \mathrm{~h}$. In the samples with elastase inhibitor added (boldtype arrows), endostatin remained un-degraded at $4 \mathrm{~h}$. By $20 \mathrm{~h}$, when the experiment was terminated, endostatin had however been degraded.

\section{Elastase activity in extracts from normal and cancerous pancreatic extracts}

Elastase activity, evaluated using the colorimetric assay described, is demonstrated for normal and pancreatic cancer tissue in Figure 5. There was a significant accumulation of product formed with time by the HBSS-soluble normal pancreatic tissue homogenate. In contrast, the pancreatic cancer tissue HBSS-soluble homogenate did not show any detectable product.

$K_{\mathrm{m}}$ for the reaction was calculated to be $1.1 \mathrm{~mm}$ using a Lineweaver-Burk plot of $1 /$ rate $v s 1 /$ substrate concentration. The slope is $K_{\mathrm{m}} / V$, the $y$ intercept is $1 / V$ and the $x$ intercept is $-1 / K_{\mathrm{m}}$.

\section{DISCUSSION}

Using Western immunoblotting we found that mature $20 \mathrm{kDa}$ endostatin is present in pancreatic cancer tissue. Endostatinrelated fragments and collagen XVIII were also present in normal pancreatic tissues but mature $20 \mathrm{kDa}$ endostatin was not detected. Collagen XVIII and the NC-1 fragments, but not endostatin, were found in the SDS-soluble fractions from both tissues and we conclude that they are not totally soluble in HBSS, consistent with membrane localisation. Whether these endostatin-related fragments have any biological activity is unknown; however, their

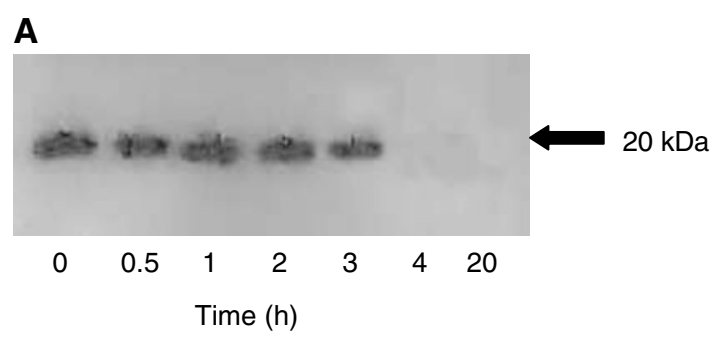

B

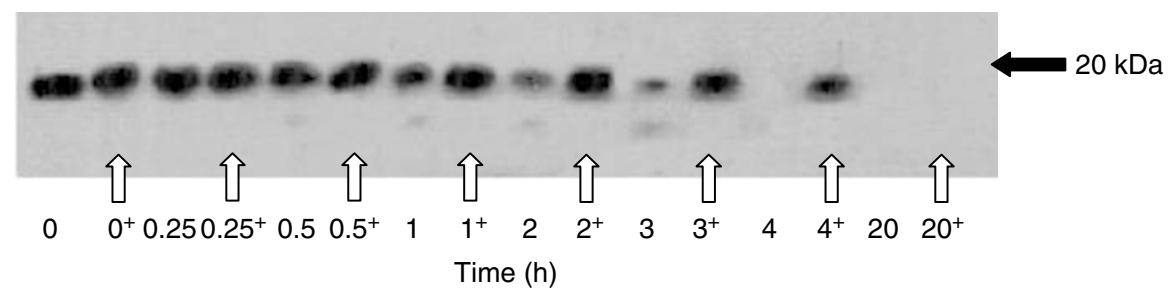

Figure 4 (A) Western immunoblotting demonstrating the effect of a chymotrypsin-trypsin inhibitor upon degradation of exogenous endostatin (5 ng) with time by normal pancreatic homogenates. (B) Western immunoblotting demonstrating the effect of the elastase inhibitor, elastatinal (I $\left.0^{-4} \mathrm{M}\right)$, on degradation of exogenous endostatin by normal pancreatic homogenates. Equal quantities of HBSS-soluble extracts of normal pancreatic tissue were incubated with $5 \mathrm{ng}$ recombinant endostatin and in the absence or presence (marked ${ }^{+}$and arrowed) of elastatinal for the indicated times. 


\section{2}

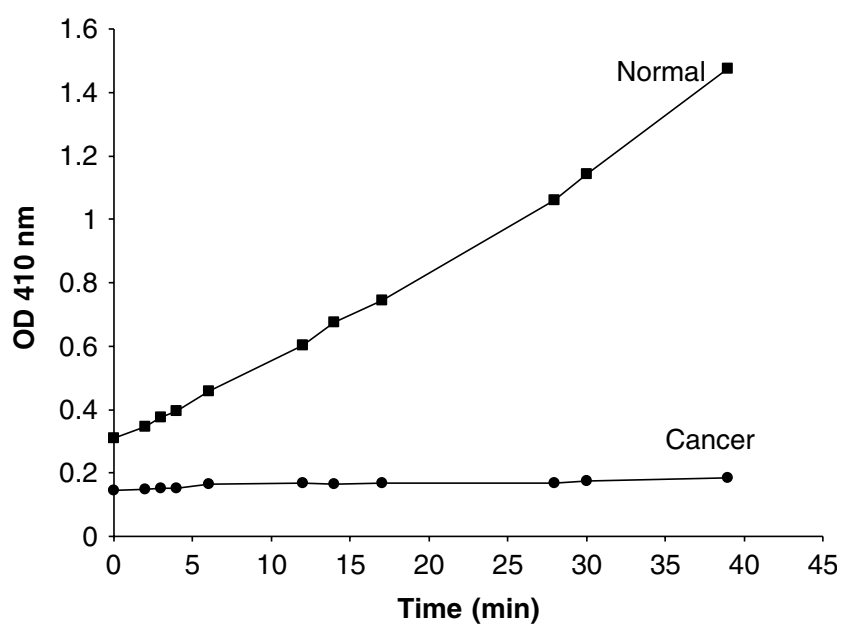

Figure 5 Elastase assay for normal and pancreatic cancer homogenates. HBSS-soluble extracts from normal and pancreatic cancer homogenates were incubated with $\mathrm{N}$-methoxysuccinyl-Ala-Ala-Pro-Val P-nitroanilide as a chromogenic substrate as described by Bieth and Wermuth (1973) Incubation was performed at room temperature on a 96-well microplate and absorbance read at $410 \mathrm{~nm}$.

presence in numerous tissues and in serum suggests a potential role as does the fact that fragments of the structurally related collagen XV inhibit angiogenesis (Marneros and Olsen, 2001; Sasaki et al, 2002).

One explanation for the absence of endostatin in normal pancreatic tissue is that endogenous endostatin can be degraded by pancreatic proteases released during the homogenisation process. We demonstrated, using exogenous endostatin, that the normal pancreas contains enzymatic activity capable of degrading both exogenous mature $20 \mathrm{kDa}$ endostatin and endogenous collagen XVIII and endostatin-related fragments. Boiling the normal pancreatic tissue extract prevented degradation of exogenous endostatin, consistent with proteolytic action. We also assayed whether varying concentrations of pancreatic cancer extract could inhibit the degradation of endostatin by normal pancreatic tissue but found no inhibition (data not shown) indicating that the effects of pancreatic cancer tissue were not due to the synthesis of a protease inhibitor.

Trypsin-chymotrypsin inhibition had no effect upon the ability of normal pancreas to degrade exogenous endostatin. This suggests that these enzymes are either not present or remain in their inactive proforms. Our studies show that elastase inhibition partially prevents endostatin degradation. Pancreatic elastase secreted into the GI tract is a protease of broad specificity and is activated in the duodenum by trypsin. We determined $K_{\mathrm{m}}$ and $V_{\max }$ for the elastase activity in the HBSS-soluble extracts. $K_{\mathrm{m}}$ was $1.1 \mathrm{mM}$, which compares with a reported $K_{\mathrm{m}}$ of $6.2 \mathrm{~mm}$ for porcine pancreatic elastase and $0.14 \mathrm{~mm}$ for human leukocyte elastase (Castillo et al, 1979). Whether the elastase that degrades endostatin is the elastase secreted into the GI tract remains unclear at present. It is certainly possible that it is a different elastase. Our data also suggest that HBSS-soluble pancreatic tissue homogenates contain other proteases capable of acting alone or in concert with elastase to degrade endostatin. Ferreras et al (2000) demonstrated that cathepsins L, B, K and D were also capable of degrading endostatin.

In contrast to normal pancreatic tissue, elastase activity was not detectable in pancreatic cancer tissue homogenates, which may explain both why mature $20 \mathrm{kDa}$ endostatin is present in pancreatic cancer tissue and why exogenous endostatin is not degraded by pancreatic cancer homogenates. Since endostatinrelated fragments were present in both normal and cancer tissues, elastase would appear to be more important in endostatin degradation than in its production.

Endostatin and endostatin-related fragments have been found in a number of tissues, which is not surprising since collagen XVIII is known to be a structural component of blood vessel walls. Endostatin release will result in a disturbance in the balance between angiogenesis promotion and inhibition, at a local level within the existing vasculature. Endostatin is known to regulate endothelial cell adhesion, survival and migration (Sasaki et al, 1998; Dhanabal et al, 1999). Conceivably following cellular injury, cellular proteases are released, which may degrade collagen XVIII completely with only transient or no production of endostatin. In this state, proangiogenic factors remain in the ascendancy and angiogenesis would result. In the absence of cellular injury and death, proteases capable of degrading endostatin are reduced and local levels of endostatin begin to rise again, restoring the balance between pro- and antiangiogenic factors. We hypothesise that endostatin is produced by proteolytic degradation of collagen XVIII in the normal population at a baseline level and is regulated by protease action rather than being produced in bursts when the body needs to reduce angiogenesis.

In cases of malignancy, in order for metastasis to occur, the balance of angiogenic factors must be biased in favour of proangiogenic factors and in favour of invasion, mediated through proteases. Pancreatic tumour cell lines are known to produce a plethora of proteases (Kitamura et al, 2000) and unusually to express receptors for angiogenic growth factors of the VEGF family (Itakura et al, 2000). Endostatin may work by inhibiting the mitogenic effects of these growth factors on the tumour cells as well as the endothelial cells (Kim et al, 2002). If tumour cells produce proteases capable of releasing endostatin from collagen XVIII, or angiostatin from plasminogen (O'Mahony et al, 1998) but do not produce proteases that are capable of degrading these antiangiogenic factors, then the tumour may be invasive but angiogenesis and metastases will be limited. In our experiments, tissue samples had been obtained from patients in whom metastasis had not occurred and it could be argued that this was because of the presence of endostatin.

We showed that elastase activity was undetectable in pancreatic cancer tissue, which is the likely explanation for why endostatin was not broken down. Patients with pancreatic tumours frequently have elevated circulating immunoreactive elastase Hayakawa et al (1990) but because higher levels are associated with a better prognosis, we suggest that this is a marker of the differentiation of the tumour. This circulating elastase is likely to be the inactive proform of pancreatic elastase, which would not thus degrade endostatin. Conversely, pancreatic tumours expressing macrophage metalloelastase have a worse prognosis than those that do not (Balaz et al, 2002). In this instance, we suggest that the elastase is active and degrades endostatin so that angiogenesis can occur as well as promoting invasion.

Folkman popularised the concept that surgical removal of tumours might remove a source of antiangiogenic factors and influence tumour biology by allowing metastatic disease to grow (Folkman, 1990, 1995). Our data support this by showing the presence and the stability of endostatin in pancreatic tumours. Tsunemi et al (2003) revealed progression of pulmonary metastases and significantly decreased serum concentrations of endostatin following removal of a primary osteosarcoma. What biological advantage endostatin production gives to the primary tumour is open to conjecture. Conceivably, there is a survival benefit due to reduced exposure to immunosurveillance. Alternatively, endostatin production may be viewed as a host defence. When the tumour secretes proteases to aid invasion, endostatin production due to collagen XVIII expression in the matrix would limit tumour spread. Only when the tumour can produce proteases, which degrade antiangiogenic factors, can metastases occur. 
The use of endostatin as an anticancer agent is an exciting thought. It is likely however, that to be most effective, extended suppression of the angiogenic process is required. Since proteases have been shown to be capable of degrading endostatin, both in vitro and in vivo, delivery of endostatin as a chemothe- rapeutic agent in the conventional sense may be difficult. Consistent with this, recent data from a mouse tumour model have shown that continuous intraperitoneal infusion is more efficacious than intravenous bolus injections (Kisker et al, 2001).

\section{REFERENCES}

Balaz P, Friess H, Kondo Y, Zhu Z, Zimmermann A, Buchler MW (2002) Human macrophage metalloelastase worsens the prognosis of pancreatic cancer. Ann Surg 235: 519-527

Bieth J, Wermuth CG (1973) The action of elastase on p-nitroanilide substrates. Biochem Biophys Res Commun 53: 383-390

Bramhall SR, Allum WH, Jones AG, Allwood A, Cummins C, Neoptolemos JP (1995) Treatment and survival in 13560 patients with pancreatic cancer, and incidence of the disease, in the West Midlands: an epidemiological study. Br J Surg 82: $111-115$

Castillo MJ, Nakajima K, Zimmerman M, Powers JC (1979) Sensitive substrates for human leukocyte and porcine pancreatic elastase: a study of the merits of various chromophoric and fluorogenic leaving groups in assays for serine proteases. Anal Biochem 99: 53-64

Dhanabal M, Ramchandran R, Waterman MJ, Lu H, Knebelmann B, Segal M, Sukhatme VP (1999) Endostatin induces endothelial cell apoptosis. J Biol Chem 274: 11721 - 11726

Ellis LM, Takahashi Y, Fenoglio CJ, Cleary KR, Bucana CD, Evans DB (1998) Vessel counts and vascular endothelial growth factor expression in pancreatic adenocarcinoma. Eur J Cancer 34: 337-340

Ferreras M, Felbor U, Lenhard T, Olsen BR, Delaisse J (2000) Generation and degradation of human endostatin proteins by various proteinases. FEBS Lett 486: $247-251$

Folkman J (1990) What is the evidence that tumors are angiogenesis dependent? J Natl Cancer Inst 82: 4-6

Folkman J (1995) Angiogenesis inhibitors generated by tumors. Mol Med 1: $120-122$

Folkman J, Klagsbrun M (1987) Angiogenic factors. Science 235: 442-447

Hayakawa T, Kondo T, Shibata T, Kitagawa M, Katada N, Kato K, Takeichi M (1990) Prospective trial for early detection of pancreatic cancer by elevated serum immunoreactive elastase. Gastroenterol Japan 25: $727-731$

Itakura J, Ishiwata T, Shen B, Kornmann M, Korc M (2000) Concomitant over-expression of vascular endothelial growth factor and its receptors in pancreatic cancer. Int J Cancer 85: 27-34

John H, Preissner KT, Forssmann WG, Standker L (1999) Novel glycosylated forms of human plasma endostatin and circulating endostatin-related fragments of collagen XV. Biochemistry 38: $10217-10224$

Jolly K, Cheng KK, Langman MJ (2002) NSAIDs and gastrointestinal cancer prevention. Drugs 62: $945-956$

Kim YM, Hwang S, Kim YM, Pyun BJ, Kin TY, Lee ST, Gho YS, Kwon YG (2002) Endostatin blocks vascular endothelial growth factor-mediated signaling via direct interaction with KDR/Flk-1. J Biol Chem 277: $27872-27879$
Kirsch M, Schackert G, Black PM (2000) Angiogenesis, metastasis, and endogenous inhibition. J Neurooncol 50: $173-180$

Kirsch M, Schaeckert G, Black PM (2004) Metastasis and angiogenesis. Cancer Treat Res 117: 285-304

Kisker O, Becker CM, Prox D, Fannon M, D’Amato R, Flynn E, Fogler WE, Sim BK, Allred EN, Pirie-Shepherd SR, Folkman J (2001) Continuous administration of endostatin by intraperitoneally implanted osmotic pump improves the efficacy and potency of therapy in a mouse xenograft tumor model. Cancer Res 61: 7669-7674

Kitamura N, Iwamura T, Taniguchi S, Yamanari H, Kawano MA, Hollingsworth K, Setoguchi T (2000) High collagenolytic activity in spontaneously highly metastatic variants derived from a human pancreatic cancer cell line (Suit-2) in nude mice. Clin Exp Metastasis 18: $561-571$

Marneros AG, Olsen BR (2001) The role of collagen-derived proteolytic fragments in angiogenesis. Matrix Biol 20: 337-345

Michell NP, Langman MJ, Eggo MC (1997) Insulin-like growth factors and their binding proteins in human colonocytes: preferential degradation of insulin-like growth factor binding protein 2 in colonic cancers. $\mathrm{Br} J$ Cancer 76: 60-66

Miosge N, Sasaki T, Timpl R (1999) Angiogenesis inhibitor endostatin is a distinct component of elastic fibers in vessel walls. FASEB $J$ 13: $1743-1750$

O'Mahony CA, Seidel A, Albo D, Chang H, Tuszynski GP, Berger DH (1998) Angiostatin generation by human pancreatic cancer. J Surg Res 77: 55-58 O'Reilly MS, Boehm T, Shing Y, Fukai N, Vasios G, Lane WS, Flynn E, Birkhead JR, Olsen BR, Folkman J (1997) Endostatin: an endogenous inhibitor of angiogenesis and tumor growth. Cell 88: 277-285

Saarela J, Ylikarppa R, Rehn M, Purmonen S, Pihlajaniemi T (1998) Complete primary structure of two variant forms of human type XVIII collagen and tissue-specific differences in the expression of the corresponding transcripts. Matrix Biol 16: 319-328

Sasaki T, Fukai N, Mann K, Gohring W, Olsen BR, Timpl R (1998) Structure, function and tissue forms of the C-terminal globular domain of collagen XVIII containing the angiogenesis inhibitor endostatin. EMBO J 17: $4249-4256$

Sasaki T, Hohenester E, Timpl R (2002) Structure and function of collagenderived endostatin inhibitors of angiogenesis. IUBMB Life 53: 77-84

Standker L, Schrader M, Kanse SM, Jurgens M, Forssmann WG, Preissner KT (1997) Isolation and characterization of the circulating form of human endostatin. FEBS Lett 420: 129-133

Tsunemi T, Nagoya S, Kaya M, Kawaguchi S, Wada T, Yamashita T, Ishii S (2003) Postoperative progression of pulmonary metastasis in osteosarcoma. Clin Orthop 407: 159-166 